\title{
AS NOVAS RELAÇÕES ENTRE ESTADO E SOCIEDADE CIVIL NA TERCEIRA VIA: MECANISMOS DE PARTICIPAÇÃO SOCIAL E ECONÔMICA NA EDUCAÇÃO
}

\author{
Camila Maria BORTOT ${ }^{1}$ \\ Angela Mara de Barros LARA²
}

\begin{abstract}
RESUMO: Tivemos por objetivo compreender como se estabelecem as relações entre Estado e Sociedade Civil na Terceira Via, em relação aos mecanismos de participação social e econômica na educação e suas intencionalidades. A reconfiguração da relação entre Estado e sociedade civil ativa a partir dos anos 2000, cujo Estado, estrategicamente, chamou a sociedade para atuar em conjunto, procurou relações consensuais. Com um Estado Catalisador, voltado ao empreendedorismo e à colaboração, o Terceiro Setor e as Redes atuam como parceiros, fazendo com que o Governo não atue unicamente na prestação direta da educação. As intencionalidades desse movimento de sociabilidade apontam à privatização do ensino público, cuja colaboração se direciona a descentralização da educação.
\end{abstract}

PALAVRAS-CHAVE: Políticas Educacionais; Estado e Sociedade Civil; Colaboração à Privatização.

ABSTRACT: This study aimed to comprehend how are established the relations between the state and Civil Society on third way, regarding the mecanisms of social participation and economic on education and its intentionalities. The reconfiguration of the relation between state and active civil society from the 2000s, whose state, strategically, invites the society to work on together, sought for consensual relations. With a catalyst state, focused on entrepreneurship and collaboration, the third sector and networks act as partners, so that the government does not act solely on direct provision education. The intentionalities of this movement of sociability point to privatization of public education, whose collaboration is directed to decentralization of education.

KEYWORDS: Educational Policies; State and Civil Society; Collaboration with Privatization.

\section{INTRODUÇÃO}

O objetivo desse artigo é compreender como se estabelecem as relações entre Estado e Sociedade Civil na Terceira Via, em relação aos mecanismos de participação social e econômica na educação e suas intencionalidades. Observou-se que as políticas educacionais têm sido elaboradas por fazedores de política com grande centralização de poder político, e, estes atuam no movimento de correlação de forças entre a classe dominante burguesa e a classe trabalhadora, em suas respectivas medidas de poder (PAULO NETTO; BRAZ, 2011). Contudo, houve uma abertura consentida como estratégia de descentralização de poderes, mesmo que limitados, a partir dessa nova relação entre Estado e Sociedade para a Educação.

Com a consolidação do neoliberalismo nas últimas décadas do século XX, a sociedade passa a ser incentivada a resolver seus problemas, inclusive sociais, tais como moradia, saúde,

\footnotetext{
${ }^{1}$ Doutoranda em Educação pela Universidade Federal do Paraná (UFPR). Mestre em Educação pela Universidade Estadual de Maringá (UEM) e Pedagoga pela mesma Universidade. Bolsista pela Coordenação de Aperfeiçoamento de Pessoal de Nível Superior (CAPES). E-mail: camilabortot@hotmail.com

${ }_{2}^{2}$ Possui graduação em Pedagogia pela Universidade Estadual de Maringá (UEM), mestrado em Educação pela Universidade Metodista de Piracicaba (UNIMEP), doutorado em Educação pela Universidade Estadual Paulista Júlio de Mesquita Filho (UNESP) e pós-doutorado pela Universidade Federal de Santa Catarina (UFSC). E-mail: angelalara@ymail.com
} 


\section{$=\mathrm{T} R A M A=$}

educação, emprego. Existiu (e existe), nesse sentido, a retirada do Estado da função de provedor desses aspectos da vida dos sujeitos. Entretanto, o Estado não se retira, totalmente, mas reconstrói-se e relocaliza-se despolitizando, mais uma vez, seu poder em benefício dos indivíduos e dos grupos pertencentes à elite econômica.

No início dos anos 2000 no Brasil, o programa neoliberal de Terceira Via se organizou e pautou-se em princípios e estratégias que buscaram uma reformulação das responsabilidades e ações do Estado e da sua relação com a sociedade civil. Baseado em atividades em que a democracia fortaleça, a sociedade civil é "[...] necessária tanto para um governo democrático eficaz quanto para um sistema de mercado que funcione adequadamente" (GIDDENS, 2001, p. 36-37). Atitudes de pertencimento e sentimento em comunidade, de ações como ajuda mútua, bem como colaboração entre classes e harmonização, nas quais os voluntários das organizações não-governamentais atuam no provimento da educação, são algumas dessas estratégias de fortalecimento que favorece uma descentralização.

Para compreender como foram organizadas tais relações, o artigo organizou-se em duas partes: elementos sobre a Terceira Via e as novas relações entre Estado e Sociedade que se configuraram a partir dos anos 2000 e, como estas relações configuram o Estado Catalisador e as Redes, a fim de entender como se estabelecem os mecanismos de participação social e econômica como estratégias para a colaboração e privatização.

\section{A TERCEIRA VIA E AS NOVAS RELAÇÕES ENTRE ESTADO E SOCIEDADE}

O contexto histórico-político-econômico e educacional em países latino-americanos, onde se insere o Brasil, no período final dos anos 1990 e início dos anos 2000, demarcam-se três momentos históricos: o primeiro entre 1986 a 1994 que se refere aos "antecedentes da implantação do projeto neoliberal de Terceira Via"; o segundo momento, de 1995 a 2006, denominado pelos autores de "primeira conjuntura do capitalismo neoliberal de Terceira Via" representa a reafirmação das diretrizes do Consenso de Washington e a configuração de uma "nova sociedade civil ativa" por meio do processo "da confrontação à colaboração"; e, o terceiro momento histórico, de 2007 a 2014, denominado de "segunda conjuntura do capitalismo neoliberal de Terceira Via", representando o processo "da colaboração para a concertação social" (MARTINS; NEVES; MELO, 2015), abarcando, de certo modo Sociedade Política e Sociedade Civil, apontando para um Estado Ampliado.

O Estado, nessa perspectiva, se direciona na compreensão de Estado ampliado, proposta por Gramsci (2014)33, por meio de dois fatores centrais: sociedade política e sociedade civil. Concomitantemente, o primeiro fator refere-se ao Estado em seu sentido restrito (os aparelhos governamentais da administração, de organização, de coerção), o que também foi denominado por Gramsci de Estado político ou sociedade política. Já a sociedade civil integraria aparelhos privados de hegemonia, no sentido da adesão voluntária de seus membros (as organizações sociais em geral).

A ampliação da sociedade civil, atribuída por Gramsci, possibilita o "desaparecimento do Estado" e a emergência de uma sociedade regulada, pois é quando a sociedade civil "absorve" a sociedade política, que torna sua concepção de mundo um referencial para a coletividade, fazendo surgir uma direção intelectual, moral e política na sociedade: a hegemonia.

\footnotetext{
${ }^{3}$ Entende-se, a partir de uma leitura de Fontes (2011), que o não isolamento entre estrutura e superestrutura na conceituação de sociedade civil apresentada por Gramsci, ao contrário "[...] a sutileza de Gramsci reside em perscrutar as formas pelas quais se constroem, socialmente, essas vontades e como estas se generalizam, considerando-se para a isso a produção material da vida (FONTES, 2011, p. 137).
} 


\section{$=$ TRAMA $=$}

Tal imbricação aponta para a construção do consenso, a organização das forças dos aparelhos privados de hegemonia e de contra hegemonia encontram, também, lugar na composição do Estado. Assim, o termo hegemonia é usado como sinônimo de construção do consenso, opondo-se à coerção pura que não deixa de ser utilizada, caso necessária, integrando força e convencimento. A sociedade civil ganha novo significado, uma vez que o projeto de Terceira Via consolidou no espaço produtivo, o trabalhador passou a ser voluntário e colaborador, contraindo o que Ball (2014) denomina de governação em rede, relações sociais e mudanças nas redes de políticas públicas, por meio das comunidades de atores e organizações sociais de influência no setor público.

Há uma construção de uma reconfiguração da relação entre Estado e nova sociedade civil ativa, cujo Estado, estrategicamente, chama a sociedade para atuar em conjunto, dando 'voz' e procurando relações consensuais. Concretizou-se um processo de redefinição jurídicopolítica das relações sociais capitalistas vigentes, ou seja, reconfigurou-se as relações entre Estado e sociedade, a partir da redefinição do papel da administração do Estado brasileiro, o que materializou o desmonte de serviços e de direitos sociais. Essa perspectiva de políticas públicas neoliberais passou a constituir um projeto de sociedade com princípios de Terceira Via, dando ênfase ao papel da sociedade civil ${ }^{4}$ como parceira ativa na proposição e implementação de políticas (NEVES, 2005; MARTINS; NEVES; MELO, 2015).

Propõe-se uma organização civil em pequenos grupos e organizações locais, articulados a partir de um objetivo comum, de nível local. A arena civil, no construto teóricoideológico-metodológico, que integra as grandes organizações, a exemplo dos sindicatos, onde "[...] devem colaborar com outros grupos, como as associações do Terceiro Setor" (GIDDENS, 2001, p. 151-152) para responder as características deste 'novo' ambiente da renovação da sociedade civil.

O Terceiro Setor é uma das alternativas propostas pela Terceira Via, tanto para que o Estado não seja mais o principal executor das políticas sociais, quanto para o que o conteúdo mercantil possa, por meio das parcerias, aprofundar a lógica do mercado nas políticas públicas, 'qualificando-as', fazendo da sociedade civil 'moderna e empreendedora'. O Governo pode oferecer apoio financeiro ou propiciar outros recursos (GIDDENS, 2001), a fim de entrar, como um novo-desenvolvimentismo, na disputa ideológica e política para a consolidação de uma estratégia de indivíduo repolitizado, que, por exemplo, o Brasil reduziria a pobreza (ou procuraria a sua conformação) e a desigualdade social produzida pelo Estado Mínimo da década de 1990, mas com os parâmetros de administração gerencial.

O papel do Estado para com as políticas sociais é alterado, pois, com esse diagnóstico duas são as prescrições: racionalizar recursos e esvaziar o poder das instituições, consideradas improdutivas pela lógica de mercado. A responsabilidade pela execução das políticas sociais deve ser repassada para a sociedade, em nome da participação e democratização, que na prática se materializa em estratégias de privatização, descentralização e publicização.

No âmbito ideológico, essa concepção tem colaborado no fortalecimento da ideia de construir uma sociedade solidária e harmoniosa com um "Estado inteligente" e "Ativo" "eficiente e competente" nas tarefas de impulsionar um modelo de desenvolvimento em harmonia com o mercado e as organizações da sociedade civil, administrando os riscos e aliviando a pobreza (GIDDENS, 1999).

\footnotetext{
${ }^{4} \mathrm{Na}$ pedagogia da hegemonia a expressão sociedade civil passou a ter sentido de espaço sem contradições ou antagonismos, sem lutas ou projetos distintos, reduzindo o termo à noção de Terceiro Setor (MELO; FALEIROS, 2005; NEVES, 2005). Relembrando que para Gramsci, a sociedade civil compreende a arena privilegiada da luta de classes, e desse modo espaço de hegemonia do grupo dominante sobre toda a sociedade (GRAMSCI, 2014).
} 


\section{$=$ TRAMA $=$}

Compreende-se que Giddens propõe não é a substituição do neoliberalismo, mas formas de mantê-lo com a ajuda das parcerias entre o governo, o mercado, as empresas e a sociedade civil, em que essa última conformada e imbricada no próprio mercado, como se os interesses vinculados aos lucros representassem os interesses da sociedade como um todo, fazendo valer a privatização e publicização da educação.

A sociedade civil tem papel ativo e decisivo no que se refere à responsabilidade sobre as políticas sociais, por isso um dos motes discursivos de Giddens (2001) é o foco na participação da sociedade civil, entendida como necessária para desonerar o Estado pesado e ineficiente. Avalia-se que há um mecanismo de hegemonia que aprofunda o processo de despolitização da sociedade civil e de esvaziamento do sentido público - reforçando a concepção liberal de sociedade civil como trama de interesses privados, porém agora mediados pelo Terceiro Setor, em conformação com as condições impostas pelo grande capital.

Williams (2003) aponta-nos analises pertinente a compreensão ao mecanismo de hegemonia, no sentido de constitui-la e disputa-la, visto acaba por incluir fatores políticos e econômicos, como os culturais; em que, para além da ideia alternativa de uma base econômica e uma superestrutura política e cultural, segundo o qual, quando a primeira mudança também modifica o segundo, que quer a primeira mudança também modificar o segundo. Isso, representa que para além do exercício da dominação, mas de que uma regra abrangente não existe apenas nas relações político e econômico, mas também em formas ativas de experiência e conscientização. A dinâmica do processo de dominação e de construir/disputar essa hegemonia " [...] não pode ser entendida no plano da mera opinião ou manipulação. Trata-se de todo um conjunto de práticas e expectativas; o investimento de nossas energias, a nossa compreensão corriqueira da natureza do homem e do seu mundo" (WILLIAMS, 2011, p. 53).

No âmbito da educação, esse mecanismo amplia o caráter economicista ou produtivista da educação inserindo novos elementos pretensamente humanizantes por meio de ações de culturais, éticas e moralmente voltados para educar a conformação da vontade. Assim, em sua aplicação política, como mecanismo de hegemonia, a parcela empobrecida da classe trabalhadora, deve investir não somente no capital humano, mas principalmente no seu capital social. Nesse sentido, Thompson (2001), enfatiza a o papel da hegemonia por meio da cultura, cujos processos educativos fazem parte da visualização de velhos problemas em novas formas, ou seja:

[...] se traduz primordialmente não na construção do modelo, mas na identificação de novos problemas, na visualização de velhos problemas em novas formas, na ênfase em normas (ou sistemas de valores) e em rituais, atentando [...] para as expressões simbólicas de autoridade, controle e hegemonia (THOMPSON, 2001, p. 229).

Dentro desse sistema de valores, de hegemonia, circularam nesses espaços públicos e privados criando uma rede de debate e de manifestações em busca da hegemonia de uma classe, da autoridade simbólica (THOMPSON, 1998; 2001).

Em busca de continuar hegemônico, o capitalismo voltado para a Terceira Via, preparou uma reforma do Estado, tanto do seu tamanho e funções, quanto de sua relação com a sociedade civil, de modo que se busque por meio de uma agenda de reformas a ampliação da esfera pública não-estatal, ou seja, a divisão de responsabilidades do Estado com o setor privado (LIMA, 2007). As escolas adentram um projeto societário, mais humanizado de parcerias, que em certa medida faz parte de mais uma estratégia que procura viabilizar esse controle social e atender demandas de mercado, ao mesmo tempo que descentraliza funções de oferta e atendimento para organizações da sociedade civil organizada. Estes elementos 


\section{$=$ TRAMA $=$}

supracitados formam um conjunto de determinações que fundamentam e explicam o contexto de ofensiva do capital contra os trabalhadores, retirando-lhes direitos, historicamente, adquiridos e mercantilizando-os na busca por campos de exploração e aumento de riquezas.

\section{PARTICIPAÇÃO NA EDUCAÇÃO COMO ESTRATÉGIAS PARA COLABORAÇÃO E PRIVATIZAÇÃO}

As políticas estatais podem ser classificadas como 'nós' do processo social, na medida em que refletem as diversas interações entre os atores sociais. O espírito de competitividade e o de solidariedade seriam desenvolvidos em paralelo, deixando de lado a perspectiva de classe e focando nas tarefas de amenização da pobreza. Gerou-se diretrizes e estratégias nas políticas educacionais pautadas na cultura de resultados e de políticas de parcerias. As políticas foram orquestradas com a perspectiva de que a educação deveria formar para o trabalho simples, atendendo desta forma os princípios educacionais da concepção hegemônica:

A formação para o simples no capitalismo neoliberal se trabalho materializa, portanto, na Educação Infantil, ensino Fundamental e ensino médio, etapas da educação, e pode ser complementadas por treinamento de habilidades específicas para ocupação de postos de trabalho. [...] disciplinando-os para o empreendedorismo e a para a colaboração (MARTINS; NEVES; MELO, 2015, p. 19-20, grifos nossos).

Concretizaram-se mudanças para um novo projeto de sociabilidade, no qual a classe trabalhadora deixou de confrontar e passou a colaborar, conduzidas por meio ao empreendedorismo e à colaboração. Sobre uma hegemonia para colaboração, na visão de Oszlak e O'Donnell (1995), uma política estatal não constitui nem um ato nem um reflexo de uma resposta isolada, mas sim um conjunto de iniciativas e respostas que permitem inferir a posição do Estado frente a uma determinada questão.

As tomadas de decisões pelo Estado frente a uma questão envolvem um caráter de negociação abertamente conflitiva. São várias as situações em que o Estado define a intervenção no processo social. Oszak e O'Donnell (1995) explicam que a intervenção do Estado supõe tomar partido seja por ação ou omissão, de forma que a sua ação positiva pode implicar:

[...] cuestión y la posición de los demás actores estén más nítidamente definidas, dejar que se resuelva en la arena privada entre las partes involucradas o considerar que la inacción constituye el modo más eficaz de preservar o aumentar los recursos políticos del régimen. Puede así imaginarse una multiplicidad de situaciones en las que el estado - a través de diversos aparatos e instancias - decide insertarse (o no) en un proceso social, en una etapa temprana o tardía de su desarrollo, con el objeto de influir sobre su curso asumiendo posiciones que potencialmente pueden alterar la relación de fuerzas de los actores involucrados en torno a la cuestión, incluyendo el propio estado (OSZAK; O'DONNELL, 1995, p. 114).

O Governo, para melhorar a atuação, procurou dar condições de libertação das vontades e liberdades individuais para plena realização no livre mercado, alterando a sua atuação e também a relação de forças dos atores envolvidos. Independente da forma de atuação, tais propostas são dissimuladoras dos seus reais propósitos na busca de possibilitar novas condições de produção e reprodução do capital. Ainda, ele se reorganizou para "orientarse para resultados", "fazer mais com menos recursos", "ser mais eficiente", "mais competitivo", "atender as necessidades dos clientes", "navegar mais em vez de remar" (OSBORNE; GAEBLER, 1994), termos que se apresentam como slogans do "espírito empreendedor" do Governo reinventado para novos padrões de sociabilidade. Para o governo ser mais eficiente 


\section{$=$ TRAMA $=$}

na prestação direta dos serviços públicos ou na indução à prestação desses serviços pelo setor privado denominado de Terceiro Setor:

[...] composto por organizações sob controle e propriedade privada, mas que existem para atender as necessidades públicas ou sociais, e não para acumular riqueza privada. Por essa definição, as grandes firmas sem fins lucrativos que existem primordialmente para acumular riqueza, não se qualificariam. Por outro lado, são incluídas as instituições com o objetivo de lucro que existe para atender a demandas sociais ou públicas (OSBORNE; GAEBLER, 1994, p. 46).

Constrói-se a ideia de que é necessário que a execução das políticas sociais passe para a responsabilidade da sociedade, principalmente, por meio das privatizações e para a Terceira Via por meio do público não estatal, do Terceiro Setor. Os governos deixam de prestar todos os serviços solicitados pela comunidade para ter uma função mais catalisadora, apoiando-se, no Terceiro Setor. As medidas destinadas a impulsionar o governo, enfatizam o aumento da exposição das próprias agências públicas de prestação de serviços a competição com outras agências públicas e empresas do setor privado; buscam, além disso, servir como catalisador deste último para consecução do objetivo público.

O papel Catalisador seria o mais importante, pois não envolveria o governo da prestação direta do serviço. Nesse sentido, a função principal do governo empreendedor se relaciona com o ato de navegar e não remar (OSBORNE; GAEBLER, 1994). O Estado se sairia melhor com a instância que definir os rumos, opera sinalizações adequadas aos agentes econômicos sociais e estimula a ação das forças da concorrência, para atingir as metas sociais desejadas, o que daria sentido a sua tarefa de navegar. Acima de tudo, o ato de remar vai contra a realidade de crise financeira do Estado.

Remar é uma atividade que exige concentração numa missão exclusiva, enquanto navegar requer que se veja todo o universo de temas e de possibilidades contrabalançando demandas diferentes que competem por recursos escassos. Nesse sentido, é preciso mais orientação governamental (ou mais navegação, trocando-se um governo que faz por um governo por um que governa junto). Osborne e Gaebler (1994) enfatizam a importância do Terceiro Setor, que também se carregaria na função de 'remar', de governar junto; bem como da importância de ter compaixão e solidariedade, que implica uma ampla confiança por parte dos clientes, necessitando de atenção direta e pessoal, envolve regras de conduta moral e responsabilidade pessoal.

A chave da Reinvenção do Governo, segundo Osborne e Gaebler (1994), é mudar os mercados que funcionam no setor público por meio da confiança e da governabilidade, aplicando a este a mesma análise do funcionamento do mercado no setor privado. Outra questão fundamental é a descentralização: as vantagens das instituições descentralizadas são as de conhecer aqui maior horizontalidade e maior flexibilidade a fim de elevar a sua eficiência.

É nesse contexto de reconfiguração da sociedade civil, da composição do Terceiro Setor e dos preceitos da Terceira Via, que se propõem de forma mais contundente e, a partir de uma construção ideológica que busca o consenso, as parcerias público-privadas, que restringem o papel do Estado na execução das políticas sociais e transfere para o "[...] público não-estatal ou Terceiro Setor, e o que permanece sob a esfera estatal passa a ter a lógica de mercado, que é considerado mais eficiente e produtivo" (PERONI; OLIVEIRA; FERNANDES, 2009, p. 764-765).

Em relação à educação, a junção dessas mudanças aponta para a possíveis fragilidades da educação pública em sua (s) forma (s) de bem-estar, no sentido de universalidade, gratuidade e responsabilidade do Estado. De acordo com Ball (2014), há um conjunto de novas 


\section{$=$ TRAMA $=$}

relações desfocadas e de interesses hegemônicos no âmbito da política e da educação pública, imbricando nesse conjunto de novas relações e interesses das parcerias público-privado, para definição e implementação da educação. De tais relações com o Terceiro Setor, as ações que são efetuadas pretendem visivelmente minimizar os investimentos em direitos sociais, tais como a educação, e significam a apropriação dos fundos públicos com a desregulamentação que é enunciada como ação modernizadora e que valoriza a sociedade civil, liberando-a do que seria a tutela do Estado.

O Terceiro Setor esteve ligado ao termo do "público não-estatal", que passou a ser utilizado a partir da reforma do Estado de 1990 no Brasil, para se referir as relações estabelecidas para o repasse de verbas públicas para instituições privadas, portanto, o público não-estatal atende plenamente as necessidades de um projeto de sociabilidade neoliberal. A educação passou a ser considerada serviço publicizado, o qual, empresas com fins educacionais ou não, podem ofertar, com verbas públicas e sob o discurso da parceria, da solidariedade e do voluntariado. Há a tendência a descentralização, que pode ser traduzida à privatização com o caráter humanizado a partir da sociabilidade das parcerias, da solidariedade e do voluntariado.

Surge neste cenário, a perspectiva de políticas públicas contemporâneas acerca da concepção de "redes" e de "governança" (ou governação), as quais têm propalado essa teoria para transformar e tornar eficientes os Estados, na implementação de suas políticas públicas, que tomaram corpus nos anos de 1980 e 1990, representando novas estruturas políticas para solucionar problemas políticos modernos.

A base de ambos os conceitos é transformar o Estado e modificar as relações entre Estado e sociedade, trazendo novos atores e concebendo redes de políticas públicas. Desse modo, o conceito de governança transcende o conceito tradicional de referir-se somente ao estatal e remete a formas adicionais de condução social, por meio de atores e instituições sociais, processo que vem formar as redes de políticas públicas, como "[...] uma nova forma de governança política" (SCHNEIDER, 2005, p. 29).

A perspectiva de composição e atuação de "redes" surgiu na contemporaneidade a partir da discussão de que era necessária uma nova forma de "governança" por parte do Estado e, para tanto, uma nova forma de implementar as políticas públicas nos países. Neste sentido, as composições de redes de atuação junto as políticas públicas passaram a construir-se e desempenhar papéis mais decisivos com participação das comunidades, movimentos sociais, associações e empresas privadas.

A concepção de Estado, portanto, se modificou: antes entendido com uma hierarquia pública, agora passa a representar uma rede de organizações. Ele envolve um sistema de múltiplos atores, com vínculos diretos e indiretos, duradouros ou não, com diferenças de poder e de influência. Tais atores atuam, ainda, como mobilizadores de recursos políticos nas situações de decisão, de formulação e de implementação de políticas.

A rede de políticas públicas evidencia uma natureza interativa do e no processo político. São analisadas conforme à sua gênese (tipo), sua composição (atores) e sua estrutura (sustentação). Quanto à gênese, as redes podem ser distribuídas em "redes fabricadas", organizadas pelo próprio estado como um mecanismo de coordenação para suportar suas políticas como as parcerias público-privadas, e "redes auto-organizadas", que se reconfiguram continuamente e são constituídas por movimentos, fóruns e associações sem a intervenção direta do Estado (LIMA, 2007). Os atores podem ter características que diferenciam as próprias redes, tais como atores individuais, coletivos, mistos, empresas, escolas, movimentos, entre outros. Estas diferenças entre os atores formam: 


\section{$=$ TRAMA $=$}

redes ego-centradas - compreendem o conjunto de atores com os quais um determinado ator focal mantém interação, bem como as relações existentes entre eles (por exemplo, todas as entidades com as quais a escola $X$ mantém uma interação regular e significativa e as relações existentes entre tais entidades);

- redes de atores individuais - constituem conjuntos de pessoas singulares e dos laços que se estabelecem entre elas (por exemplo, movimentos pedagógicos que unem educadores em rede, como é o caso do Movimento da Escola Moderna);

— Redes de atores coletivos — são formalmente idênticas às anteriores, com a exceção de que, neste caso, cada ator da rede é uma pessoa coletiva (uma empresa, uma escola, um movimento associativo, etc.);

— redes mistas — compreendem conjuntos mistos de atores individuais e coletivos;

— meta-redes — são redes de atores coletivos "de segunda ordem": cada ator na rede é, ele próprio, uma rede — dito de outro modo, trata-se de "redes de redes" (LIMA, 2007, p. 174).

Essa gestão nas políticas brasileiras por meio das redes, pode ser entendida como Governabilidade ${ }^{5}$, de parceria entre Estado e sociedade civil, entre atuações estatais e não estatais ligadas ao Terceiro Setor. A relação entre Estado e sociedade civil nos anos 2000, permitiu a criação de agências de orientação, conforme denominado por Osborne e Gaebler:

Quando os governos separam a direção de suas políticas da prestação e serviços, descobrem muitas vezes que não estão realmente capacitados a cumprir a primeira dessas responsabilidades. Seus vários departamentos [...] são ativados pela prestação de serviços. O gerenciamento das políticas públicas é objeto de improvisação, quando existe. À medida que os governos adotam uma função mais catalisadora, são forçados a criar novas agências para executar o seu papel de orientador da comunidade a que servem (OSBORNE; GAEBLER, 1994, p. 194).

Apreende-se que o Governo que atua conjuntamente com a sociedade civil, ao exercer apenas uma função regulatória, permite que atores sociais participem das políticas buscando novos consensos, que, na verdade, fazem parte de estratégias hegemônicas amparadas na Terceira Via. Contudo, em tais brechas, alguns agentes desarticulam tais proposições ligadas apenas ao projeto hegemônico econômico, deixando de vê-los (estudantes, educadores, sociedade em geral) apenas como os que sofrem os efeitos das determinações do Estado e de sua desarticulação social, realizando espaços de correlação de forças para além de um campo desigual e excludente, o que propicia a disputa de projetos e desse campo hegemônico.

A legitimidade adquirida por essas organizações do Terceiro Setor frente ao Estado, aos organismos internacionais e ao mercado, no trato às questões de políticas sociais, é significativa nas últimas décadas. Contudo, o Estado Socializante, abordado por Santos (2006) se faz cada vez mais imprescindível em tal dinâmica do 'toma lá, da cá' das políticas sociais:

Estado é indispensável, porque as organizações do Terceiro Setor não são abarcativas, elas não podem cuidar do conjunto de pessoas que precisam de cuidados. Elas acabam obrigadas a cuidar mais de um de certos setores, e não de outros setores. Enquanto que o Estado, através do exercício da política, a tendência dele é cuidar de todos, de todas as pessoas. Essa é a produção democrática, realmente democrática, que as ONGs e Terceiro Setor não podem, pela sua própria definição, porque tem limitações de sua origem, de seu financiamento e de seus objetivos. Então, o Estado se torna algo cada vez mais indispensável, porque as fontes criadoras de diferenças, de desigualdades são muito mais fortes do que no passado, então, para desmanchar essas diferenças, reduzir essas

\footnotetext{
${ }^{5}$ Conceito gerencial que na perspectiva do projeto neoliberal se refere a uma forma específica de atuação do Estado representa sustentabilidade política, econômica e social do governo. Neste ideário, com governabilidade o Estado se torna mais moderno e mais eficiente (NEVES, 2005).
} 


\section{$=\mathrm{T} R A M A=$}

desigualdades, é necessário um Estado que intervenha, um Estado Socializante (SANTOS, 2006 , grifos nossos).

Observa-se um esforço na tarefa de convencer sobre a necessidade da participação da sociedade civil na educação, de exercer a hegemonia. A formação de redes sociais que são compostas por um conjunto de pessoas e ou organizações que se agregam com interesse comum, contribuem para a produção e disseminação de informações, criam canais de comunicação e estimulam a participação da sociedade. Ao mesmo tempo em que procuram produzir consenso em torno do projeto que defendem, qual seja: o das parcerias públicoprivadas para o atendimento educacional nas escolas públicas, e, para além a articulação de outros arranjos educativos de Terceiro Setor com tendências à privatização do ensino público.

\section{CONSIDERAÇÕES FINAIS}

A discussão travada ao longo do artigo permitiu compreender como se estabeleceram as relações entre Estado e Sociedade Civil na Terceira Via, a fim de apreender como se constroem os novos mecanismos de participação social e econômica na educação e suas intencionalidades. Intencionalidades estas que envolvem as redes, as relações do público nãoestatal ou do público-privado, o Terceiro Setor, na busca de sustentar o Estado Catalisador e Socializante das novas relações entre Estado e Sociedade Civil na Terceira Via.

Os mecanismos de participação social e econômica na educação se direcionam, mesmo que ressignificados pelo discurso de que todos colaboram na construção e na efetivação da política educacional, à privatização do ensino público. O percurso teórico desenvolvido aponta que o esforço na tarefa de convencer sobre a necessidade da participação da sociedade civil na educação, se apresenta como uma estratégia do capital de exercer a sua hegemonia, mas que é necessário, por meio de tais espaços, lutas contra hegemônicas.

A articulação em redes de colaboração em que se inserem as agências de orientação é tão importante para manutenção da hegemonia do capital, e, por esse motivo, as redes sociais e o Terceiro Setor são fundamentais a partir da Terceira Via, seja na elaboração de políticas ou no seu financiamento, atuando para a descentralização e a privatização da educação.

\section{REFERÊNCIAS}

BALL, S. J. Educação global S. A.: novas redes políticas e o imaginário neoliberal. Tradução de Janete Bridon. Ponta Grossa: UEPG, 2014.

CASTELO, R. O Social-liberalismo: auge e crise da supremacia burguesa na era neoliberal. 1. ed. São Paulo: Expressão popular, 2013.

FALLEIROS, V. P. A política social no Estado capitalista. SP: Cortez, 2005.

GIDDENS, A. A terceira via e seus críticos. Rio de Janeiro: Record, 2001.

GIDDENS, A. A Terceira Via: reflexões sobre o impasse político atual e o futuro da socialdemocracia. Rio de Janeiro: Record, 1999.

GRAMSCl, A. Caderno 12 (1932): Apontamentos e notas dispersas para um grupo de ensaios sobre a história dos intelectuais. Cadernos do Cárcere, vol. 2. Edição e tradução Carlos Nelson Coutinho, co-edicação Luiz Sérgio Henriques e Marco Aurélio Nogueira. $7^{a}$ ed. Rio de Janeiro: Civilização Brasileira, 2014.

LIMA, J. Á. Redes na educação: questões políticas e conceptuais. Revista Portuguesa de Educação, Lisboa, Portugal: Universidade do Minho, v. 20, n. 2, p. 151-181, 2007.

MARTINS, A. S.; NEVES, L. M. W.; MELO, A. A. S. et al. Educação Básica: tragédia anunciada? São Paulo: Xamã, 2015

NEVES, L. M. W. A sociedade civil como espaço estratégico de difusão da nova pedagogia da hegemonia de difusão da nova pedagogia da hegemonia. In: NEVES, L. M. W. (Org.). A nova pedagogia da hegemonia: estratégias do capital para educar o consenso. São Paulo: Xamã, 2005. p. 85-126.

OSBORNE, D.; GAEBLER, T. Reinventando o governo: como o espírito empreendedor está transformando o setor público. Brasília: MH Comunicação, 1994.

${ }^{6}$ Citação extraída do filme MILTON SANTOS- Por uma outra globalização. Direção de Sílvio Tendler. Brasil, 2006. Color, Digital, $54 \mathrm{~min}$ 
OSZLAK, O.; O'DONNELL, G. Estado y políticas estatales en América Latina: hacia una estrategia de investigación. Centro de Estudios de Estado y Sociedad (CEDES), Documento G.E. CLACSO, 1995: Buenos Aires, Argentina. p. 11-23.

PAULO NETTO, J.; BRAZ, M. Economia Política: uma introdução crítica. SP: Cortez, 2011.

PERONI, V.; OLIVEIRA, R.; FERNANDEZ, M.; Estado e Terceiro Setor: as novas regulações entre o público e o privado na gestão da educação básica brasileira. Educação e Sociedade, Campinas, vol. 30, n. 108, p. 761778, out. 2009.

SCHNEIDER, V. Redes de políticas públicas e a condução de sociedades complexas. Civitas - Revista de Ciências Sociais, Porto Alegre, v. 5. n. 1, p. 29-58, jan./jun. 2005.

THOMPSON, E. Desencanto ou apostasia? In: THOMPSON, E. Os românticos: a Inglaterra na era revolucionária. Rio de Janeiro: Civilização Brasileira, 2001. p. 49-101.

Costumes em comum. São Paulo: Cia das Letras, 1998.

WILLIAMS, R. Palabras claves. Buenos Aires: Nueva Vision, 2003.

Recebido em 10-04-2018.

Aceito em 10-08-2018. 